\title{
Protecting the environment during armed conflict: fragilities in the provisions of international humanitarian law
}

\author{
${ }^{1}$ Mahbubul Islam \\ ${ }^{1}$ Senior Lecturer, Department of Law, Eastern University, Dhanmondi, Dhaka, Bangladesh
}

\begin{abstract}
War is a common phenomenon throughout the history of mankind. It causes not only human sufferings and crippling injuries on the battlefield but also extensive destruction and degradation of the environment. Some battlefields of the First and Second World Wars, for example, still remain unfit for cultivation or unsuitable for human habitation due to the unexplored devices, mines and projectiles embedded in the soil. The Vietnam War and the 1991 Gulf War are also two glaring examples where the environment itself was used as a weapon of mass destruction. It is noteworthy to mention that environmental damage caused by war may have transborder as well as intergenerational effect on population. It can have transboarder effect in the sense that the impacts of environmental contamination are not limited to the countries in which the wars are waged as air and water pollution can be carried across boundaries threatening the health of populations in neighboring regions. In the same way, experiencing from Hiroshima, Nagasaki, and some parts of Iraq it can be concluded that the environmental damage that is occurring during armed conflicts may threaten the very survival of our future generation on this planet. The international humanitarian law (IHL) whose purpose is to control the conduct of the parties in the armed conflict is deficient to protect environment in wartime. The approach of international humanitarian law (IHL) to protect the environment during armed conflict is fragmented, piecemeal and not comprehensive. In this article, the author explores the structural deficiencies and fragilities of the provisions of contemporary international humanitarian law to protect environment during armed conflict.
\end{abstract}

\section{INTRODUCTION}

Environment helps to sustain human life on this earth. It is the air we breathe, the food we eat and the water we drink. As the ICJ declared in 1996, in its Advisory Opinion on the Legality of the Threat or Use of New Clear Weapons: "The environment is not an abstraction but represents the living space, the quality of life and the very health of human beings, including generation unborn "[1] But, environmental damage is inevitable in most armed conflicts. Throughout history, war has always left its mark on the environment. Israel invasion on Gaza has destroyed fourteen thousand living trees. The accumulated effects of the environmental damage in the 1991 Gulf War which was mainly caused by the torching and flooding of oil-wells in Kuwait, the spilling of oil from Kuwait and Iraq into the Persian Gulf, and by the military action of both sides during the conflict was disastrous. Damage locations were widespread, affecting not only Kuwait and Iraq but also Saudi Arabia, Iran, and other neighboring countries in the Gulf. Due to the Earth's rotation and the normal winds on the area, some effects were reported in Afghanistan, Pakistan, and India and, even in the Himalayan peaks between China, Tibet and Nepal. ${ }^{[2]}$ To assess damage caused in 1991 Gulf War including environmental damage and to receive compensation from Iraq, the UN Security Council created the United Nations Compensation Commission ${ }^{[3]}$ and affirmed in its Resolution 687 (1991) that Iraq "without prejudice to the debts and obligations [...] arising prior to 2 August 1990, which will be addressed through the normal mechanisms, is liable under international law for any direct loss, damage, including environmental damage and the depletion of natural resources, or injury to foreign Governments, nationals and corporations, as a result of Iraq's unlawful invasion and occupation of Kuwait (part E, paragraph 16). ${ }^{,[4]}$ UNEP's 2003 post-conflict environmental assessment found that after two decades of war, Afghanistan's natural resource base had largely been destroyed. The degradation of the natural resources upon which some 80 percent of Afghans depended for their livelihoods was a critical problem across the country. ${ }^{[5]}$ Chemical and biological weapons, which have long lasting effect, are being used during armed conflict. Some conventional weapons like cluster bomb and weapons have mass destruction can have intergenerational effect on population. Therefore, the ICJ in the Nuclear Weapons Case asserts that States must take environmental considerations into account when assessing what is necessary and proportionate in the pursuit of legitimate military objectives ${ }^{[6]}$ Destroying environment has a lasting psychological as well as sociological impact on the population and may have intergenerational effect. In some areas of Iraq, to give an example, babies born without eyes, ears or legs etc. International humanitarian law (IHL), whose purpose is to make war more humane, is deficient to protect environment during armed conflict. The protections that IHL 
offer for the environment during armed conflict are inadequate. This paper will outline the extent to which the environment is protected during armed conflict.

\section{PROTECTION OF ENVIRONMENT UNDER INTERNATIONAL HUMANITARIAN LAW AND FRAGILITIES THEREOF:}

The provisions of IHL that are directly relevant for environmental protection during armed conflicts contain numerous ambiguities and deficiencies which are detailed below.

\section{Additional Protocol I to the 1949 Geneva Conventions}

Articles 35(3) and 55 of Additional Protocol I to the 1949 Geneva Conventions have directly addressed environmental harm and degradation, and attempted to shield the environment from destructive weapons during armed conflicts.

Paragraph 3 of Article 35 stipulates that-

"It is prohibited to employ methods or means of warfare which are intended, or may be expected, to cause widespread, long term and severe damage to the natural environment."

This Article thus directly focuses on the protection of the natural environment during armed conflict and applies not only to intentional damage, but also to expected collateral damage. Success of this provision was in recognizing the necessity for the first time to take care of or protecting natural environment even during armed conflict.

Again Article 55 of the Protocol I stipulates that-

"1. Care shall be taken in warfare to protect the natural environment against widespread, long-term and severe damage. This protection includes the prohibition of the use of methods or means of warfare which are intended or may be expected to cause such damage to the natural environment and thereby to prejudice the health or survival of the population.

2. Attacks against the natural environment by way of reprisals are prohibited."

Fragilities of these provisions to protect the natural environment:

The common core of these two Articles is the prohibition of warfare that may cause "widespread, long-term and severe damage to the natural environment". Though apparently these provisions appear to be extensive to protect the natural environment, however, important questions remain with regard to the threshold at which the damaging activities violate international law.

By the provisions of these two Articles, only those means and methods are prohibited which cause or expected to cause widespread, long-term and severe damage to the natural environment. So, if the damage is only widespread or only long term or only widespread and long term but not severe, in that situation these two Articles provide no protection to the natural environment. This triple standard is a cumulative requirement, meaning that to qualify as prohibited the impact of the damage must be at the same time widespread, long term and severe. Moreover, one of the blatant fragility of these two Articles is that the terms "widespread, long term and severe" are not defined in the protocol and for this reason there remains the risk of abuse of these terms and thereby cause harm to the natural environment. The protocol fails to define these terms, resulting in a high, uncertain and imprecise threshold. One commentary on Article 35(3) has accordingly noted that it would "not impose any significant limitation on combatants waging conventional warfare. It seems primarily directed instead to high-level decision makers and would affect such conventional means of warfare as the massive use of herbicides and agents which could produce widespread, long-term and severe damage to the natural environment."Paragraph 2 of Article 55 prohibits attacks on the environment by way of reprisals. This provision indirectly recognizes the attack on environment by any modes other than reprisals. Article 54(2) of the said Additional Protocol I also indirectly protects the environment by prohibiting attacks against "objects indispensable to the survival of the civilian population," meaning objects that are of basic importance to the population's livelihood. As per Article 48 of the Additional Protocol I military operations must be directed only against the combatants and military objectives but the definition of civilian objectives as mentioned in Article 52(2) of the Additional Protocol I is ambiguous and confusing which may frustrate the protection sought to be provided to the natural environment during armed conflict.

UN Convention on the Prohibition of Military or Any Other Use of Environmental Modification Techniques [ENMOD] (1976)

The ENMOD Convention was established as a reaction to the military tactics employed by the United States during Viet Nam war and also as a reaction to the use of large quantities of chemical defoliants (known as Agents Orange, White and Blue).

These included plans for large-scale environmental modification techniques that had the ability to turn the environment into a weapon, for instance by provoking earthquakes, tsunamis, or changes in the weather patterns. 
Article 1 of ENMOD, 1976 stipulates that-

"Each state party to this convention undertakes not to engage in military or any other hostile use of environmental modification techniques having widespread, long-lasting or severe effects as the means of destruction, damage or injury to any other state party."

The ENMOD Convention aims to prevent the use of environmental modification techniques as a weapon. And for that very purpose Triple cumulative standard, as it was in the case of Additional Protocol I to the Geneva Conventions 1949, has been relaxed to any of those standard i.e. widespread, long-lasting or severe. But these standards of ENMOD will not be applicable for the protocol I as the purposes of the protocol I and the ENMOD convention are different and non-identical.

\section{FRAGILITY OF ENMOD TO PROTECT ENVIRONMENT DURING ARMED CONFLICT:}

UNEP helped to convene the negotiations that led to the ENMOD Convention; it has not had a systematic role in monitoring its implementation and enforcement. The state party under ENMOD Convention only accepts an undertaking to perform their obligation under the convention but what will be the consequence if these undertakings are not fulfilled is not specified. This convention will apply only when the environmental modification techniques by one state party will cause damage, destruction or injury to another state party and it has no application to protect the natural environment in national armed conflict. It is pertinent to note here that the protocol I and the ENMOD convention have different applications, purposes and thresholds, with no substantive overlap. The Protocol is aimed at protecting the natural environment against damage which could be inflicted on it by any destructive weapons, whereas the goal of the Convention is to prevent the use of environmental modification techniques as a weapon.

\section{Convention on Prohibition or Restrictions on the Use of Certain Conventional Weapons which May Be Deemed to Be Excessively Injurious or to Have Indiscriminate Effects (CCW), and its Protocol III on Prohibitions or Restrictions on the Use of Incendiary Weapons (1980)}

The CCW states in its preamble that-"It is prohibited to employ methods or means of warfare which are intended, or may be expected, to cause widespread, long-term and severe damage to the natural environment."

Article 2(4) of the CCW Protocol III on Prohibitions or Restrictions on the Use of Incendiary weapons prohibits-"making forests or other kinds of plant cover the subject of an attack by incendiary weapons except when such natural elements are used to cover, conceal, or camouflage combatants or other military objectives, or are themselves military objectives."

\section{Deficiency of CCW and its Protocol III to protect natural environment}

The specific situations where ENMOD and the CCW and its protocol III would apply limit the utility of these direct protections in establishing a wide-reaching duty to protect the environment in armed conflict.CCW and its Protocols also requires the triple standard of widespread, long-lasing and severe damage to be proved to attract its provisions and thereby frustrates the environmental protection intended to provide hereunder.

Under Article 2(4) not every elements of environment rather only forests and other kinds of plant are intended to provide protection. Under the above mentioned Article even forests and other kinds of plant are excluded from the protection when they are used to cover, conceal or camouflage the combatants or where these elements are in themselves military objectives.

\section{CONCLUSION}

Protection of environment is not the core concern of IHL. Only those types of environmental degradation are prohibited under the provisions of IHL which are at the same time widespread, long-term and severe. Widespread, long-term and severe these terms are not defined in the provisions of four Geneva Conventions or in its Two Additional Protocols or in any other IHL documents. Some provisions of IHL focus specifically to prohibit some weapons which have the tendency to damage the natural environment but due to scientific and technological development these provisions cannot apply to the newly invented weapons of warfare which also have the same likelihood to destroy the natural environment. The rules of IHL for the protection of the environment therefore aim not to prevent damage altogether, but rather to limit it to a level deemed tolerable. The ICJ in the Nuclear Weapons Case made special note of the UN General Assembly Resolution on the Protection of the Environment in Times of Armed Conflict ${ }^{[7]}$, which affirms that environmental considerations constitute one of the elements to be taken into account in the implementation of 
the principles of the law applicable in armed conflict. The Resolution also proclaims that "destruction of the environment, not justified by military necessity and carried out wantonly, is clearly contrary to existing international law" ${ }^{\text {"[8] }}$. But, the attempts of humanitarian laws to protect environment find no way to work on because of the over emphasis on military necessity. Therefore, the approach of IHL to protect the environment during armed conflict is fragmented, piecemeal and not comprehensive. So, more comprehensive protection of the environment in armed conflict shall be ensured. We can suggest that Additional treaty protection could be created for objects of special environmental importance deserve careful consideration. The idea of military operation, the means and methods of warfare would be shaped in such a way that armed conflict will not remain as a threat to the natural environment.

[1] Advisory Opinion on Legality of the Threat or Use of New Clear Weapons, ICJ Reports 1996, 226 et seq., (241, Para. 29)

[2] W.M. Arkin, D. Durran \& M. Cherni, On Impact: Modern Warfare and the Environment, A Case Study of the Gulf War 68-69 (1991).

Resolution 692 (20 May 1991).

[3] Iraq's responsibility was affirmed in Resolutions 666 (13 September 1990), 670 (25 September 1990), 674 (29 October 1990), and 686 (2 March 1991).

[4] UN Environment Program (2003), Afghanistan post-conflict environmental assessment. UNEP, Geneva as referenced in Matthew, et al., p. 23

[5] The ICJ Advisory Opinion on the Legality of the Threat or Use of Nuclear Weapons, Advisory Opinion of 8 July 1996.

[6] UN Doc. A/RES/47/37 (1992)

[7] The ICJ Advisory Opinion on the Legality of the Threat or Use of Nuclear Weapons, Advisory Opinion of 8 July 1996, Para 32 